\title{
Editorial
}

\section{Opening the Black Box}

As I have been transitioning into the editor role, it has become clear that there is confusion about the editorial and review process for CERL. There have been numerous discussions on aspects of the process-selection, review, timeline-and other questions and misapprehensions.

In the spirit of open access and transparency, this editorial will attempt

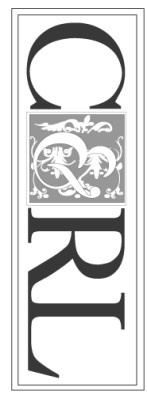
to demystify the process, verify the integrity of the journal, and explain the journal's standards and expectations while demonstrating how it is positioned and supported.

\section{Open Access Model in an Outsourced Environment}

College $\mathcal{E}$ Research Libraries is a gold open access publication, financially supported through ACRL membership dues. The online journal is freely available. There is a movement in scholarly publishing to use open source software for journal hostingboth as a way to model the values of open access and to decrease the administrative costs and regain control of the process. I have seen journal management from a number of different models: a completely commercial model with Elsevier, a completely OA model on an Open Journal Systems platform (from configuration to publication) and a mixed model with $C \mathcal{E} R L$, which is OA on a commercially hosted platform. There are benefits and drawbacks to each: the more involved a commercial publisher is, the less control the editor and board have to make changes and enhancements (and the bigger the dollar sign attached); the closer to OA a journal is, the more reliant on volunteer service and the more potential for "homegrown" solutions. It will be quite interesting to see how these models evolve and how CERL evolves with them.

\section{Submission and Review}

The primary way in which we can open the black box of peer review and editing is to define it. To that end, we have actually codified the workflow of the journal with approximate intervals for major stages of the process.

Regarding this workflow, I would like to point out a few details.

The editorial staff (the editor or assistant editors) review all incoming submissions for:

- relevance to the journal

- $\quad$ originality of research or innovative practice (and how generalizable it may be)

- $\quad$ rigor of method and/or data (using this term very broadly)

- adherence to journal guidelines and engaging writing style

A percentage of articles make it no farther-this is referred to as a desk-reject and it may not include as much feedback as a peer-reviewed article because it does not meet one of these primary screening criteria. This process usually takes between 2 and 4 weeks.

If the article meets these standards, then the editor will select at least 2 peer reviewers with expertise on the topic who will be invited to review. This is an invitation that the reviewer may decline; if they accept, they are given 28 days to review. Depending on the time of year, there may be a larger number of declines, no responses, or late reviews. Peer reviewers are volunteers with regular jobs, so these periods tend to coincide with busier times or times of hiatus. Understandably, these situations will prolong the review process. 
Editorial 565

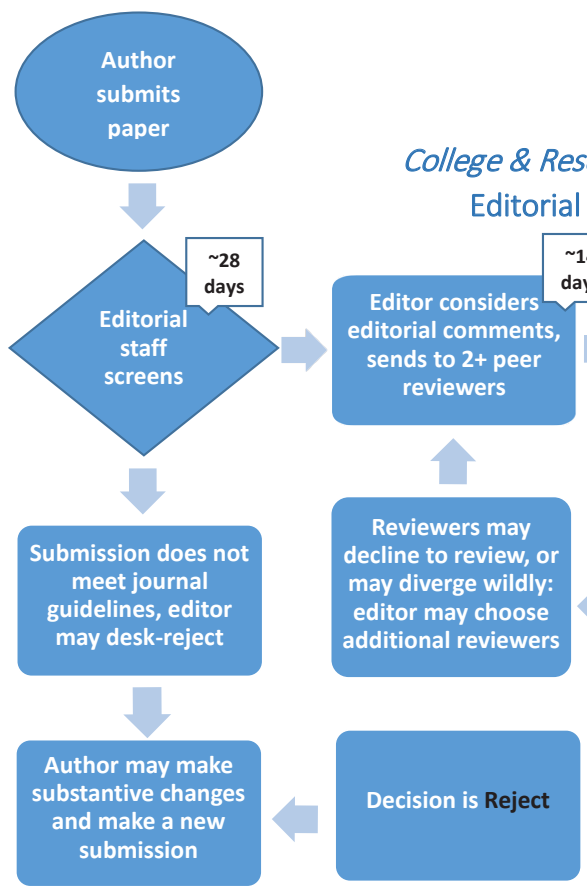

evaluate and make

recommendation

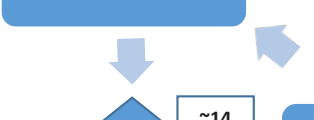

decline to review, or

may diverge wildly:

editor may choose

additional reviewers

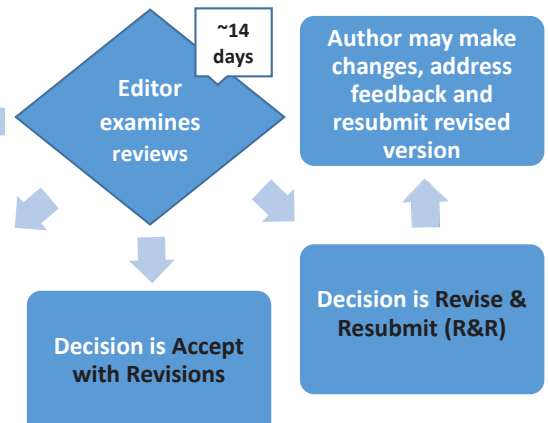
revisions

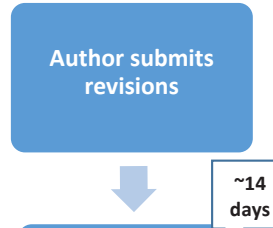

Editor checks that suggested changes were addressed and Accepts
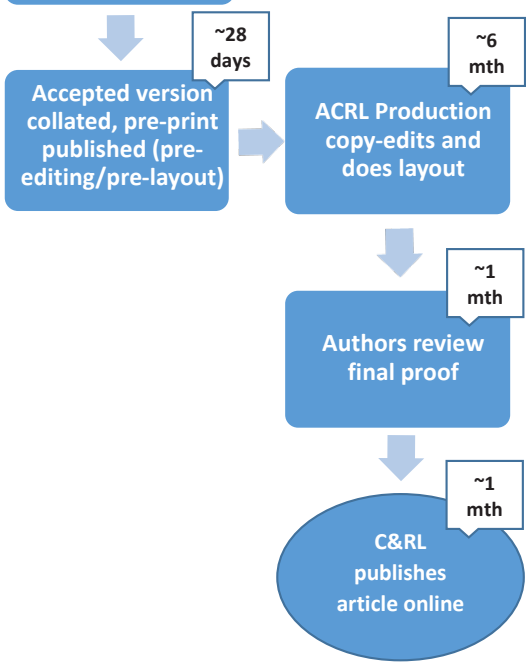
In some cases, the peer reviewers wildly disagree about a submission-one may indicate to accept while the other says reject. In this instance, the editor will read the comments, review the paper again, and make a determination or, possibly seek a third reviewer if both reviews make valid points.

Once the submission has completed review, the editor considers the reviews and may add additional comments. The extent of the comments varies and, in most cases, the editor will include the comments as written by the peer reviewer-this is also intended to contribute to the transparency of the process. In cases where the feedback may be conflicting, the editor will clarify and may weigh in with one recommendation over the other.

\section{Revised Submissions}

As always, the author is empowered to revise, ignore, or respond to the feedback. In my opinion, as both an editor and an author, the more feedback the better. As an author, I have received reviews that were bleeding with comments and suggestions - and it can be demotivating. Knowing this, I like to advise authors that the number of comments should be considered a measure of how much effort a reviewer has put into the evaluation - that if the reviewer did not see potential in the submission, he or she would not have invested the time in the review to make it the best article it could be.

This topic of author submissions was the subject of extended discussion at the Editorial Board meeting in Orlando this summer, where there was agreement that authors and reviewers needed more information and guidance about the process and best practices. There were a number of suggestions to help support authors and reviewers while providing clarity around the standards and expectations of the journal. These suggestions will be the focus of some administrative efforts with the journal this year.

One of the discussions was specifically about mentoring authors. The Editorial Board, peer reviewers, and I, are all committed to providing objective feedback to authors in an effort to get the best results and provide guidance for the authors in their research and writing. Each manuscript is reviewed on its own merits. The process is double blind: the authors do not know who is reviewing their submission and, through anonymization of the manuscripts, the reviewers do not know who has submitted the manuscript. While it makes the process objective, it also imposes some barriers to providing help or mentoring to authors beyond a written review. As a remedy, we will be using ACRL's subscription to LibGuides and will create a Guide for Authors and a Guide for Reviewers that will each address logistical components of the editorial submission system and provide detailed information about the journal's standards and expectations. Lastly, we will also be creating some videos that will feature researchers and recognized authors in the field discussing research and writing.

\section{From Acceptance to Publication}

Before addressing the somewhat contentious topic of time to publication, let me provide a reminder and a caution about the acceptance process: while the time to publication is months, the time to acceptance is more immediate and the accepted article is made public as a preprint about 6 weeks after acceptance. Let me repeat that - the accepted article is what is published as a preprint. This means that any changes that an author wishes to make to formatting, citations, co-authors, etc., must be done prior to acceptance. Because the journal is hosted on a commercial hosting platform, there is a cost to make changes or even remove a preprint from the site. That being the case, even submissions that have no significant changes recommended will be Accept with Revisions with the explicit reminder about the pre-print publication and any final changes. 
Note that the lag from acceptance to publication is approaching a year. Having a few months of publication lag is deliberate. While authors (and readers) understandably want a very short window from acceptance to publication, there is magic that occurs behind the scenes (in terms of copy-editing, final layout, and author approval of the final copy). In addition, there needs to be enough content in the pipeline to accommodate the ebb and flow of submissions and any unforeseen circumstances. Again, since peer reviewers are volunteers, much of their work reviewing submissions fits in around their "real jobs" and other commitments. Part of that ebb in activity tends to occur around semester breaks when many reviewers are on break. Having been coeditor of a journal that had been essentially on a review hiatus for 6 to 8 months when I came on board, we had to scramble to review, edit, and layout articles because there was nothing in the pipeline at all! That said, the ideal time for acceptance to publication is about 8 to 9 months. In an effort to reduce the current timeline from 12 months, the publications team and I have been working together (thanks Dawn and David!) and have identified a number of accepted articles under a cohesive topic. This means there will be an additional special topic issue published in the Spring of 2017 on Scholarly Communication and Open Access that will help reduce the current lag time.

I realize there are a lot of minute details about the process and policy here that may seem mundane or bureaucratic, but in an effort to be more transparent about the process and more supportive of authors, this is how the sausage is made.

P.S. As I was in the process of finalizing this editorial, one of the few blogs I read came across referring to a buzzfeed that made me laugh hysterically - because, sadly, it is also true: "15 Funny Lines That Somehow Slipped Into A Scientific Journal" provides some interesting illumination into the writing process while underscoring the importance of final editing.

Wendi Arant Kaspar Texas A\&M University

\section{Note}

1. Cowley, Scott. "15 Funny Lines That Somehow Slipped Into A Scientific Journal." https:// www.buzzfeed.com/scottcowley/15-ridiulously-funny-lines-that-somehow-slipped-in-17xu6. 